\title{
Hypertension and Clustering of Cardiovascular Risk Factors in a Community in Southeast Brazil - The Bambuí Health and Ageing Study
}

\author{
Sandhi Maria Barreto, Valéria Maria Azeredo Passos, Josélia O liveira Araújo Firmo, \\ Henrique Leonardo Guerra, Pedro Guatimosim Vidigal, Maria Fernanda Furtado Lima-Costa \\ Belo Horizonte, MG - Brazil
}

\begin{abstract}
Objective - A population-based prospective study was analysed to: a) determine the prevalence of hypertension; b) investigate the clustering of other cardiovascular risk factors and c) verify whether older differed from younger adults in the pattern of clustering.
\end{abstract}

Methods - The data comprised a representative sample of the population of Bambuí, Brazil. Multiple logistic regression was used to investigate the independent association between hypertension and selected factors.

Results - A total of 820 younger adults $(82.5 \%)$ and 1494 older adults (85.9\%) participated in this study. The overall prevalence of hypertension was $24.8 \%$ ( $S E=1.4 \%$ ), being higher in women $(26.9 \pm 1.5 \%)$ than in men $(22.0 \pm$ $1.7 \%)(p=0.033)$. Hypertension was positively and significantly associated with physical inactivity, overweight, hypercholesterolemia hyperglycemia and hypertriglyceridemia. The coexistence of hypertension with 4 or more of these risk factors occurred 6 times more than expected by chance, after adjusting for age and sex $(O R=6.3 ; 95 \% C I$ : 3.4-11.9). The pattern of risk factor clustering in hypertensive individuals differed with age.

Conclusion - Our results reinforce the need to increase detection and treatment of hypertension and to approach patients' global risk profiles.

Keywords: hypertension, cardiovascular risk factors, prevalence

\footnotetext{
Faculdade de Medicina, Universidade Federal de Minas Gerais, Centro de Pesquisas Rachou, Fundação Oswaldo Cruz - Belo Horizonte

Mailing address: Sandhi Maria Barreto - Laboratório de Epidemiologia e Antropologia Médica, Centro de Pesquisas René Rachou - Av. Augusto de Lima, 1715 - 30190-002 - Belo Horizonte, Brasil - e-mail: sbarreto@cpqrr.fiocruz.br Received for publication on $01 / 29 / 01$

Accepted on 4/4/01
}

Epidemiological data show that hypertensive individuals are remarkably different from normotensive persons in more than just high blood pressure (BP). A tendency exists for hypertension to occur in combination with other lifestyle, metabolic, and anthropometric factors, all independently associated with increased risk of cardiovascular diseases (CVD). According to data from the Framingham Heart Study, less than $20 \%$ of hypertension occurs in the absence of 1 or more risk factors, including high triglycerides and LDL cholesterol levels, reduced HDL cholesterol levels, glucose intolerance, hyperinsulinemia, obesity, and left ventricular hypertrophy ${ }^{1}$.

Cardiovascular diseases are the leading cause of death in Brazil, accounting for $34 \%$ of all deaths in $1990-94^{2}$, and the main cause of hospitalisation in those aged $\geq 60$ in $1996^{3}$. The country's population is ageing very rapidly, and the social and economic burden associated with CVD is likely to grow. Until recently, CVD were supposed to be a problem of adults living in the large metropolitan areas of Brazil. However, around 27 million Brazilians live in urban areas of small municipalities, and little is known about their risk profile. We investigated hypertension as a risk factor syndrome in younger and older adults living in a small municipality in Southeast Brazil that was also formerly an endemic area for Chagas' disease $^{4,5}$.

We analysed data from the baseline of the Bambuí Health and Ageing Study (BHAS), which comprises a community survey and an ongoing prospective study designed to identify predictors of adverse health events in older adults ${ }^{4}$. The objectives of this study are: a) to describe BP levels and the prevalence of hypertension in the adult population living in a community in Southeast Brazil, b) to compare hypertensive and normotensive individuals in relation to the presence of other cardiovascular risk factors including metabolic, anthropometric, and lifestyle factors, and c) to verify whether older adults differ from younger adults in the overall pattern of risk factor clustering. 


\section{Methods}

Bambuí is located in West Minas Gerais State, in Southeast Brazil. The municipality had around 20,000 inhabitants in 1996, of which $73 \%$ were living in the urban area. Agriculture and commerce are the main economic activities of the municipality. Life expectancy increased from 59.9 in 1970 to 70.2 years in 1991. Cardiovascular diseases (ICD-9: 390-459) were the primary cause of death in Bambuí in 1991 $(34 \%)$ and the second cause of hospitalisations in the public sector in 1993 (18,5\%). In Bambuí, even though transmission of Trypanosoma cruzi has now been interrupted, the prevalence of the infection is very high among the aged due to a cohort effect ${ }^{5}$.

Participation in the study was voluntary, and a signed copy of an informed consent was obtained from all participants.

The BHAS includes an initial baseline survey and follow-up activities. Complete censuses were carried out for identification of participants. All residents aged $\geq 60$ years $(n=1742)$ and a nonreplaceable simple probabilistic sample of adults aged 18-59 years were selected for interview and examinations. The sample size of adults (1020/8899 inhabitants) was sufficient to estimate a prevalence of risk factors $=0.50$, with a confidence interval $=0.95$, losses $=0.20$, and precision $=0.03$.

In the present study, the baseline cohort data $(\geq 60$ years) and the cross-sectional study data (18-59 years) were analysed. Interviews, physical measurements, blood samples, and blood tests of all participants were accomplished between January and August 1997. Further details of the methods used to conduct the study have been published elsewhere ${ }^{4}$.

The following information obtained in the BHAS baseline survey questionnaire was used in this analysis: 1) social and demographic characteristics (age, sex, personal and family income, graduation level, marital status),2) lifestyle characteristics (physical activities, smoking and drinking habits), and 3) clinical aspects (use of antihypertensive medication). The interview lasted about 90 minutes and was performed at home. Neither interviewer nor interviewee knew about the objectives of this study at the time of the interview.

Health professionals especially trained for this project took BP and physical measurements of all participants at the local health service. BP was measured 30 or more minutes after the last caffeine intake or cigarette smoked. Systolic and diastolic BP(SBP and DBP) were recorded as the first and fifth Korotkoff sounds, respectively. Three measures were taken after 5 minutes of initial rest and subsequently at 2-minute intervals. In this study, BP was considered as the arithmetic mean of the second and third measurements ${ }^{5}$. The nutritional indicator used was body mass index (BMI = weight/square height), and measures were taken by specially trained health technicians, using standard equipment ${ }^{4}$.

Blood samples were collected after for 12 hour fasting. Plasma levels of glucose, total cholesterol, HDL cholesterol, and tryglicerides were determined using an automated analyser (Eclipse Vitalab, Merck, The Netherlands). LDL cholesterol was estimated using the Friedewald equation ${ }^{6}$. Consequently, information on LDL cholesterol was regarded as missing for levels of triglycerides equal to or greater than $400 \mathrm{mg} / \mathrm{dL}$. The presence of $T$. cruzi antibodies was detected using an indirect hemaglutination test and an enzyme linked immunoabsorbent assay (Biolab and Abbott Brazil, respectively).

Hypertension was defined as DBP $\geq 90 \mathrm{mmHg}$, or SBP $\geq 140 \mathrm{mmHg}$ or current use of antihypertensive medication for management of hypertension, at the time of interview ${ }^{7}$. We determined 4 study subjects were hypertensive by asking them and also by checking to antihypertensive medications at their homes. If both were affirmative, the subject was classified as having hypertension irrespective of the blood pressure obtained.

Estimates were weighted to allow for the difference in sampling probability of participants aged 18-59 years (younger adults) and those aged $\geq 60$ years (older adults) and to represent the total urban adult population. Descriptive statistics were used to fully explore the data. One sample $t$ test was used for comparisons between means and designbased Pearson's chi-square test for proportions.

To investigate the tendency of hypertension to cluster with other cardiovascular risk factors, we created a risk factor score to rank individuals according to the number of other known risk factors for CVD existing at the time of the survey. The following factors and cut-off points were used to build up this risk factor score: 1) $\mathrm{BMI} \geq 25 \mathrm{~kg} / \mathrm{m}^{2}, 2$ ) total cholesterol $\geq 240 \mathrm{mg} / \mathrm{dL}$ and/or LDL-cholesterol >160mg/dL, 3) HDLcholesterol $<50 \mathrm{mg} / \mathrm{dL}$ in males or $<45 \mathrm{mg} / \mathrm{dL}$ in females, 4 ) triglyceride $>150 \mathrm{mg} / \mathrm{dL}, 5$ ) blood glucose $\geq 126 \mathrm{mg} / \mathrm{dL}, 6$ ) current smoker, and 7) physical inactivity (walking or doing some other kind of exercise less than once per week and a self-report of having a sedentary life). The final risk factor score varied from 0 to 4 , with 0 meaning no exposure to these factors, 1 being the exposure to any 1 factor and 2, 3, and 4 being exposure to any combination of 2,3 , or 4 or more of these factors, respectively.

The magnitude of the association between hypertension and independent variables was investigated using multiple logistic regression ${ }^{8}$. The analysis was carried out using Stata Statistical Software ${ }^{9}$.

\section{Results}

The total number of participants in this study was 820 individuals aged $18-59$ years ( $82.5 \%$ of the selected sample) and 1494 individuals aged $\geq 60$ years ( $85.9 \%$ of residents).

The prevalence of hypertension in the adult population of Bambuí was $24.8 \%$ (SE: 1.14), being higher in women $(26.9 \pm 1.5 \%)$ than in men $(22.0 \pm 1.7 \%)(p=0.033)$. Figure 1 shows the prevalence of hypertension according to sex and age group. The prevalence of hypertension increased with age for males and females up to age group 60-69 years, and was much lower for very old ( $\geq 80$ years) males than females in the same age group ( $43 \%$ vs. $68 \%$, respectively). 


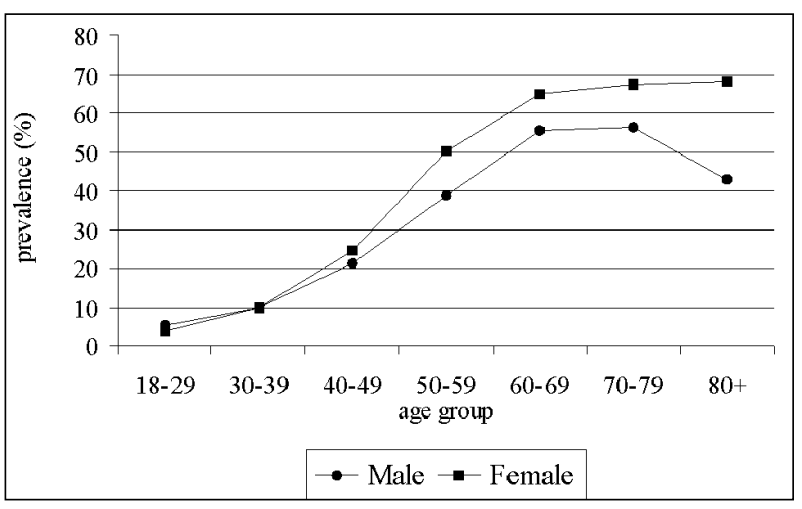

Fig. 1 - Prevalence of hypertension in the urban adult population of Bambuí according to sex and age group. BHAS, 1996-97.

Forty-two percent of younger and $51 \%$ of older adults were classified as having stage I hypertension ( $\mathrm{SBP}=140-159$ or DBP $=90-99)^{7}$. A slightly higher proportion of younger adults $(20 \%)$ than older adults $(13 \%)$ were classified as having stage $2(\mathrm{SBP}=160-179$ or $\mathrm{DBP}=100-109)$, and similar percentages as having stages 3 or 4 hypertension $(\mathrm{SBP} \geq 180$ or $\mathrm{DBP} \geq 110$ ) (11\% and 13\%, respectively). Ageing was also associated with an increasing severity in levels of BP, expressed by higher levels of mean SBP with increasing age in men and women, with a slight decrease in the mean level for very old men ( $\geq 80$ years) (Figure 2 ). The mean levels of both SBP and DBP were lower in women during early adulthood than in men. Pulse pressure (SBP minus DBP) was highest for very old ( $\geq 80$ years) women (Figure 2 ).

Isolated systolic hypertension (ISH), defined as SBP $\geq 140 \mathrm{mmHg}$ and DBP $<90 \mathrm{mmHg}$, regardless of medication status, was found in $18.9 \%$ of the individuals with hyperten- sion. This proportion was around $1 \%$ up to age $40-49$ years increasing sharply thereafter $(7.9 \%, 12.9 \%, 21.7 \%$, and $20.7 \%$ in age groups 50-59, 60-69, 70-79, and $\geq 80$ years, respectively). Defining ISH as $\mathrm{SBP} \geq 160 \mathrm{mmHg}$ and DBP $<95 \mathrm{mmHg}$ reduced the overall prevalence of ISH to $4.9 \%$, being $9.3 \%$ among the older and $1.4 \%$ among younger adults.

The results of the logistic regression analysis on the association of hypertension with socio-demographic characteristics and lifestyles are presented as raw and after adjustment for age and sex (Table I). Current smoking and inactivity remained associated with hypertension status after adjustment for age and sex, with prevalences being lower in current smokers and higher in inactive persons. $\mathrm{BMI} \geq 25 \mathrm{~kg} / \mathrm{m}^{2}$ and $\geq 30 \mathrm{~kg} / \mathrm{m}^{2}$ were highly associated with hypertension before and after adjustment for age and sex. Hypertension status was not statistically associated with schooling or family income after adjustment for age and sex.

All metabolic factors (total cholesterol, HDL and LDLcholesterol, triglycerides, and glucose) were significantly associated with hypertension status before and after adjustment for age and sex. The association between T. cruzi infection and hypertension found in the univariate analysis disappeared after adjustment for age and sex (Table II).

The average number of linked metabolic and lifestyle risk factors for CVD increased with age, in both hypertensive and normotensive persons. However, the average number of risk factors was higher for individuals with hypertension at in all age groups compared $(1.32,1.57$, and 1.98 in normotensive persons aged 18-39, 40-59, and $\geq 60$ years vs. $2.03,2.13$, and 2.31 in hypertensive persons in the same age groups). In hypertensive individuals, only $6 \%$ of younger and $8 \%$ of older adults were not simultaneously exposed to

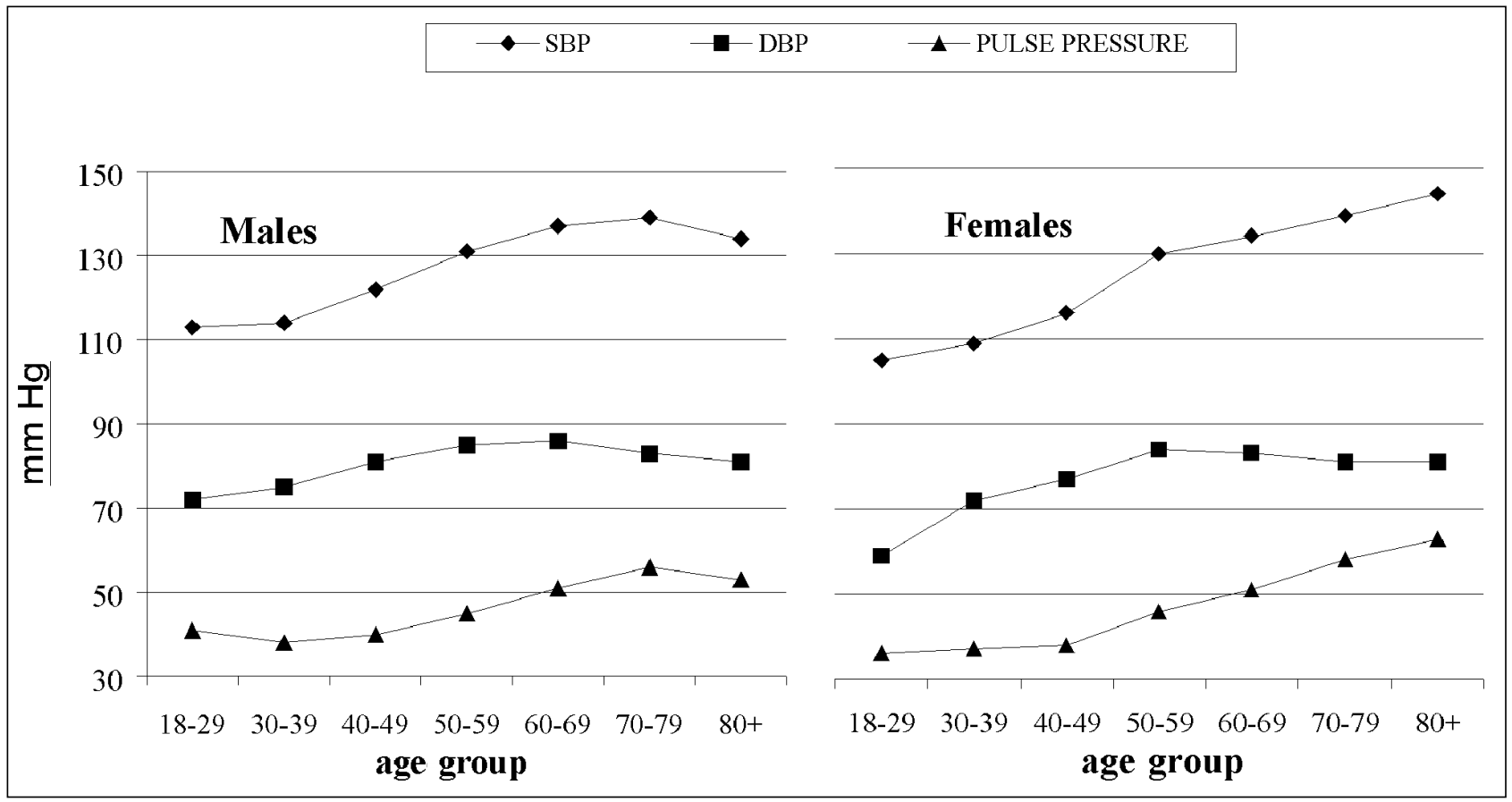

Fig. 2 - Mean systolic and diastolic blood pressures and pulse pressure by age for men and women 18 years of age and over. BHAS, $1996-97$. 


\begin{tabular}{|c|c|c|c|c|}
\hline \multirow[b]{2}{*}{ Factor } & \multicolumn{2}{|c|}{ Hypertension } & \multirow{2}{*}{$\begin{array}{l}\text { Odds ratio } \\
(95 \% \mathrm{CI})\end{array}$} & \multirow{2}{*}{$\begin{array}{l}\text { Adjusted } \\
(95 \% \mathrm{CI})\end{array}$} \\
\hline & No $(\mathrm{n}=1256)$ & Yes $(n=1058)$ & & \\
\hline \multicolumn{5}{|l|}{ Sex } \\
\hline Male & 570 & 377 & 1.00 & 1.00 \\
\hline Female & 686 & 681 & $1.30(1.02-1.67)$ & $1.30(0.96-1.75)^{1}$ \\
\hline \multicolumn{5}{|l|}{ SLiteracy (years) } \\
\hline None & 206 & 323 & 1.00 & 1.00 \\
\hline $1-3$ & 288 & 339 & $0.62(0.43-0.90)$ & $1.03(0.68-1.56)$ \\
\hline $4-7$ & 427 & 302 & $0.26(0.18-0.37)$ & $0.75(0.49-1.15)$ \\
\hline $8+$ & 335 & 94 & $0.12(0.08-0.18)$ & $0.62(0.36-1.05)$ \\
\hline \multicolumn{5}{|c|}{ Family monthly income (minimum wage) } \\
\hline$<2$ & 288 & 299 & 1.00 & 1.00 \\
\hline $2-3.99$ & 464 & 387 & $0.64(0.47-0.88)$ & $0.87(0.59-1.29)$ \\
\hline $4-5.99$ & 237 & 167 & $0.58(0.40-0.84)$ & $0.97(0.61-1.55)$ \\
\hline $6-9.99$ & 133 & 104 & $0.52(0.33-0.82)$ & $0.93(0.54-1.61)$ \\
\hline $10+$ & 116 & 93 & $0.56(0.35-0.89)$ & $0.85(0.49-1.48)$ \\
\hline \multicolumn{5}{|l|}{ Smoking } \\
\hline Never & 671 & 642 & 1.00 & 1.00 \\
\hline Ex-smoker & 344 & 175 & $0.51(0.37-0.64)$ & $0.93(0.63-1.36)$ \\
\hline Current smoker & 241 & 241 & $1.16(0.86-1.58)$ & $0.60(0.41-0.88)$ \\
\hline \multicolumn{5}{|c|}{ Physically active ${ }^{3}$} \\
\hline No & 256 & 361 & 1.00 & 1.00 \\
\hline Yes & 1000 & 697 & $0.34(0.26-0.45)$ & $0.59(0.41-0.84)$ \\
\hline \multicolumn{5}{|c|}{ Body mass index (kg/m2) } \\
\hline$<25$ & 766 & 434 & 1.00 & 1.00 \\
\hline $25-29$ & 355 & 410 & $2.69(2.05-3.52)$ & $2.82(2.02-3.94)$ \\
\hline$\geq 30$ & 107 & 184 & $4.30(2.99-6.20)$ & $4.29(2.75-6.70)$ \\
\hline
\end{tabular}

\begin{tabular}{|c|c|c|c|c|}
\hline \multicolumn{5}{|c|}{$\begin{array}{c}\text { Table II - Association between hypertension and selected } \\
\text { laboratory examinations, raw and after adjustment for sex and } \\
\text { age group. BHAS, 1996-97 }\end{array}$} \\
\hline \multirow[b]{2}{*}{ Factor } & \multicolumn{2}{|c|}{ Hypertension } & \multirow[b]{2}{*}{$\begin{array}{c}\text { Odds ratio } \\
(95 \% \mathrm{CI})\end{array}$} & \multirow{2}{*}{$\begin{array}{l}\text { Adjusted } \\
\text { Odds ratio } \\
(95 \% \text { CI })\end{array}$} \\
\hline & $\begin{array}{c}\text { No } \\
(n=1256)\end{array}$ & $\begin{array}{c}\text { Yes } \\
(\mathrm{n}=1058)\end{array}$ & & \\
\hline \multicolumn{5}{|c|}{ Cholesterol (mg/dL) } \\
\hline$<200$ & 632 & 269 & 1.00 & 1.00 \\
\hline $200-239$ & 358 & 359 & $2.74(2.03-3.69)$ & $1.51(1.06-2.14)$ \\
\hline$\geq 240$ & 266 & 430 & $5.28(3.85-7.24)$ & $1.89(1.27-2.82)$ \\
\hline \multicolumn{5}{|c|}{ HDL Cholesterol $\geq 45$ (men) or $\geq 50 \mathrm{mg} / \mathrm{dL}$ (women) } \\
\hline Yes & 682 & 522 & 1.00 & 1.00 \\
\hline No & 572 & 534 & $1.32(1.04-1.68)$ & $1.46(1.07-1.99)$ \\
\hline \multicolumn{5}{|c|}{ Triglycerides (mg/dL) } \\
\hline$<150$ & 931 & 593 & 1.00 & 1.00 \\
\hline$\geq 150$ & 323 & 463 & $2.51(1.94-3.24)$ & $2.03(1.49-2.75)$ \\
\hline \multicolumn{5}{|c|}{ Blood glucose (mg/dL) } \\
\hline$<126$ & 1191 & 916 & 1.00 & 1.00 \\
\hline$\geq 126$ & 63 & 140 & $4.75(2.89-2.78)$ & $1.86(1.08-3.22)$ \\
\hline \multicolumn{5}{|c|}{ Serology for $\mathrm{T}$. cruzi } \\
\hline Negative & 997 & 691 & 1.00 & 1.00 \\
\hline Positive & 251 & 359 & $4.05(3.01-5.46)$ & $1.11(0.77-1.59)$ \\
\hline
\end{tabular}

the metabolic and lifestyle risk factors considered in this stu$\mathrm{dy}$. The corresponding figures in normotensive individuals were $23 \%$ and $10 \%$, respectively. Conversely, the proportion of persons exposed to 3 or more risk factors was $31 \%$ and $42 \%$ in hypertensive individuals aged $18-59$ and $\geq 60$ years, respectively and $15 \%$ and $33 \%$ in normotensive persons in the same age groups.
The raw and sex and age-adjusted odd ratios (OR) for each level of the risk scores are given in Table III. A clear and steep upward trend exists in the sex and age-adjusted OR for being hypertensive with increasing risk factor scores, with a highly significant $x^{2}$ for linear trend. The magnitude of the age-adjusted OR for risk factor scores was similar for men and women. Inclusion of educational level in the multivariate analysis had a negligible effect on the OR for risk factor score and was not kept in the final analysis.

The pattern of risk factor clustering in hypertensive individuals differed significantly with age $\left(\chi^{2}=10.05, P=0.0\right.$

\begin{tabular}{|c|c|c|c|c|}
\hline \multicolumn{5}{|c|}{$\begin{array}{l}\text { Table III - Odds ratios for hypertension according to the score of } \\
\text { other cardiovascular risk factors, raw and after adjustment for age } \\
\text { and sex. BHAS, 1996-97 }\end{array}$} \\
\hline \multirow[b]{2}{*}{$\begin{array}{l}\text { Risk factor } \\
\text { score }^{1}\end{array}$} & \multicolumn{2}{|c|}{ Hypertension } & \multirow[b]{2}{*}{$\begin{array}{c}\text { Odds-ratio } \\
(95 \% \mathrm{CI})\end{array}$} & \multirow{2}{*}{$\begin{array}{l}\text { Age-adjusted } \\
\text { Odds-ratio } \\
(95 \% \mathrm{CI})\end{array}$} \\
\hline & $\begin{array}{c}\text { Yes }(\%) \\
(n=1026)\end{array}$ & $\begin{array}{c}\text { No }(\%) \\
(n=1223)\end{array}$ & & \\
\hline Zero & 76 & 208 & 1.00 & 1.00 \\
\hline One & 222 & 395 & $2.54(1.60-4.06)$ & $2.48(1.49-4.13)$ \\
\hline Two & 305 & 334 & $3.52(2.22-5.58)$ & $2.87(1.72-4.80)$ \\
\hline Three & 245 & 197 & $6.09(3.73-9.94)$ & $4.33(2.48-7.55)$ \\
\hline Four or more & 178 & 89 & $10.71(6.15-18.65)$ & $6.33(3.38-11.86)$ \\
\hline \multicolumn{5}{|c|}{$\begin{array}{l}{ }^{1} \text { : Risk factor score: defined as the sum of any combination of the following } \\
\text { factors: } 1 \text { ) BMI } \geq 25 \mathrm{~kg} / \mathrm{m}^{2}, 2 \text { ) total cholesterol } \geq 240 \mathrm{mg} / \mathrm{dL} \text { and/or LDL- } \\
\text { cholesterol }>160 \mathrm{mg} / \mathrm{dL}, 3 \text { ) HDL-cholesterol }<50 \mathrm{mg} / \mathrm{dL} \text { in males or }<45 \\
\mathrm{mg} / \mathrm{dL} \text { in females, 4) triglyceride }>150 \mathrm{mg} / \mathrm{dL}, 5 \text { ) blood glucose } \geq 126 \mathrm{mg} / \\
\mathrm{dL}, 6 \text { ) current smoker, and 7) physical inactivity. }\end{array}$} \\
\hline
\end{tabular}


$40)$, inactivity $\left(\chi^{2}=8.77, P=0.003\right)$, hyperglycemia $\left(\chi^{2}=7.83\right.$, $\mathrm{P}=0.005)$, and hypercholesterolemia $\left(\chi^{2}=28.61, \mathrm{P}<0.001\right)$ being more common in older adults and overweight $\left(\chi^{2}=15.51\right.$, $\mathrm{p}<=0.001)$ being more common in younger adults.

\section{Discussion}

This study found that about $1 / 4$ of the population in this community is hypertensive. Most adults had stage 1 hypertension, but over $28 \%$ had BP levels beyond 160/ $100 \mathrm{mmHg}$ (stages 2,3, or 4), and this proportion was highest in older men (around 40\%). The prevalence of hypertension in the older population living in this community is very high $(61.5 \%)$, and surprisingly close to that described for the American population in the same age group ${ }^{10}$.

The overall prevalence of hypertension in this study community is similar to that found in São Paulo, the largest Brazilian city with over 10 million inhabitants ${ }^{11}$, and smaller than that found in other studies in the country ${ }^{11-13}$. Discrepancies in the age range and sex distribution among the study populations in these surveys are likely to account for such differences. The variation in the prevalence of hypertension with age in both sexes is very similar to prevalence curves described in cross-sectional studies in Brazil ${ }^{14,15}$ and in other countries ${ }^{16-18}$.

The increase in pulse pressure with age observed in this community has been associated with ISH, and predicted CVD in a continuous graded fashion at all levels of BP in the Framingham Study ${ }^{19}$. The prevalence of ISH is seldom mentioned in Brazilian studies, perhaps because it is much more common in older age groups, and none of the studies on hypertension were designed to study older adults. We found a much lower prevalence of ISH among hypertensive older adults in Bambuí (26.7\%) than observed in the older adults participating in the Framingham Study (65-75\%) and the US population aged $\geq 60$ years $(65 \%)^{19,20}$. The rise in SBP with advancing age is attributed to loss of arterial compliance and this process is unlike that of atherosclerosis, which underlies the preponderance of CVD observed in older people ${ }^{16}$. Combined systolic and diastolic hypertension, which predominates in this study community, seems to carry only a marginally greater risk than ISH ${ }^{20}$. The low prevalence of ISH may be partly explained by the younger age of older adults in this community as compared with Americans studied, but it is also likely to express population differences in prevalence of risk factors affecting systolic and diastolic BP levels.

Hypertension was not associated with any of the socio-demographic variables in this study after adjustment for age and sex. Some Brazilian studies have found an association between hypertension and educational level ${ }^{13,15,21}$, but they were conducted in large cities with greater socio-economic contrasts than our study community, where agriculture is the main economic activity. In this community, educational level decreases with age. About $24 \%$ of younger and $64 \%$ of older participants have less than 4 years of graduation. This fact may have reduced the ability to detect any possible association with educational level in our study.
Regarding the comparison of hypertensive and normotensive individuals, the results are worrisome: only $7 \%$ of hypertensive individuals were not exposed to other metabolic or lifestyle risk factors. All metabolic factors investigated were associated with hypertension independently of age and sex. These findings agree with previous investigations on the tendency of hypertension to occur concomitantly with other metabolic disorders ${ }^{3}$. The importance of this clustering relates to its great impact on the risk of CVD. Lipoproteins greatly affect the impact of hypertension on atherogenesis, and high cholesterol (especially HDL cholesterol) and triglyceride levels markedly influence the risk of hypertension-induced coronary disease. Similarly, the risk of coronary artery disease is also greatly increased by coexisting glucose intolerance ${ }^{19}$. Smoking was associated with a lower prevalence of hypertension. This finding agrees with other cross-sectional studies in the country ${ }^{15}$ and elsewhere ${ }^{19}$, and is probably explained by the worse survival of hypertensive smokers and lifestyle changes induced by disease.

Lack of regular physical activity was also related to a high prevalence of hypertension in other studies ${ }^{13,15,22 .}$. It is now accepted that exercise plays a direct and etiological role in BP levels and should be part of a global approach to treatment of hypertension. Exercise seems to have a protective effect on premature death and coronary artery disease even when started late, regardless of patients' age and how long they have been sedentary ${ }^{23}$.

The association between BMI and hypertension has been observed in other cross- sectional studies in Brazil ${ }^{13,15}$. Strong epidemiological evidence exists that overweight increases the risk of hypertension and CVD, independent of age or levels of plasma glucose and serum cholesterol. Obesity, particularly abdominal adiposity, has been found to promote insulin resistance, which is related to hypertension in a graded fashion ${ }^{1}$.

In our study, the combined prevalence of selected metabolically linked risk factors increased as the population aged, both in hypertensive and normotensive individuals, but prevalences were greater in those with hypertension in all age groups and differences were wider in younger adults. After adjustment for age and sex in the regression analysis, we found that the prevalence of hypertension increased directly with the number of risk factors examined. Because hypertension is variably hazardous depending on the number and severity of associated risk factors ${ }^{1}$, the very high prevalence of coexisting risk factors in hypertensive individuals in this community has important public health and therapeutic implications. The use of a simple score, such as the one used in this study, allows classification of hypertensive individuals according to their global risk profile. The coexistence of hypertension with 4 or more lifestyle and metabolically linked risk factors was 6 times higher than expected by chance, after taking age and sex into account. It is no longer appropriate to consider reduction in hypertension as the sole goal of antihypertensive therapy ${ }^{19-21}$.

Our results indicate that differences in multivariate risk profile of hypertensive individuals are less striking in older 
adults when compared with younger ones. However, the high prevalence of metabolic disorders and inactivity in the aged and the high proportion of older individuals with overt CVD tend to magnify the impact of apparently small differences in risk profile on morbidity and mortality. In this community, around $20 \%$ of older adults had symptoms or a previous medical diagnosis of CVD.

In the BHAS, all efforts were made to avoid bias: encouraging participation, collecting information double blinded, assessing the reliability of the data gathered, standardised procedures and instruments, and exhaustive training of field work and laboratory teams. The participation rate was high, and older and younger participants were similar to the town population regarding sex, age, marital status, monthly family income, and education ${ }^{4}$. However, because of the cross-sectional nature of the data, one cannot discard the possibility of survival bias: 1) older participants are survivors (i.e., those exposed to risk factors have a higher probability of dying prematurely);2) older participants are noninstitutionalised (i.e., those living in the community tend to be healthier). No institution for older adults exists in Bambuí. At any rate, a survival bias in this study would tend to reduce the magnitude of the associations found, favouring the direction of our results.
In conclusion, the high prevalence of hypertension and the clustering of CVD risk factors in hypertensive individuals in this community indicate the need not only to increase detection and control of hypertension in this community, but also to direct treatment to improve individuals' global risk profiles. Around 27 million Brazilians live in small towns like the one investigated in this study, and very little is known about their health conditions. Because we have no reason to suppose that the population of Bambuí differs from those of other towns of similar size, it is reasonable to inquire about the extension and implications for health care services of the cardiovascular risk profile pictured in this study.

\section{Acknowledgement}

We thank all the people included in the BHAS who gave free and informed consent before their participation in this study. This research was conducted in full accordance with ethical principles of the Declaration of Helsinki (as amended by the $48^{\text {th }}$ General Assembly, Somerset West, South Africa). The Brazilian Agency of Studies and Projects (FINEP) supported this study. SM Barreto, VMA Passos, and MFF Lima e Costa are fellows of the National Research Council (CNPq),Brazil. HL Guerra is the recipient of a fellowship from CNPq.

\section{References}

1. Kannel WB. Risk stratification in hypertension: new insights from the Framingham study. Am J Hypertens 2000; 13: 3S-10S

2. Pan American Health Organization. A saúde no Brasil 1998; 32.

3. Lima e Costa MFF, Guerra HL, Barreto SM, Guimarães RM. Diagnóstico da situação de saúde da população idosa brasileira: um estudo da mortalidade e das internações hospitalares públicas. Inf Epidemiol SUS 2000; 9: 23-41.

4. Lima e Costa MFFL, Uchôa E, Guerra HL, Firmo JOA, Vidigal PG, Barreto SM. The Bambuí Health and Ageing Study (BHAS). Methodological approach and preliminary results of a population-based cohort study of the elderly in Brazil. Rev Saúde Pública 2000; 34: 126-35.

5. Lima e Costa MFF, Barreto SM, Guerra HL, Firmo JOA, Uchoa E, Vidigal PG. Ageing with Trypanosoma cruzi infection in a community where the transmission has been interrupted: the Bambuí Health and Ageing Study (BHAS). Int J Epidemiol (in press).

6. Joint National Committee. The fifth report of the Joint National Committee on Detection, Evaluation, and Treatment of High BP. Arch Int Med 1993; 153: 154-83.

7. Friedewald WT, Levy RI, Frederuckson, DS. Estimation of the concentration of low-density lipoprotein cholesterol in plasma without use of the preparative ultracentrifuge. Clin Chem 1972; 18: 499-502.

8. Hosmer DW, Lemenshow S. Applied logistic regression. John Wiley and Sons; New York: 1989

9. Stata Statistical Software (computer program). Release 6.0 College Station, Texas: Stata Corporation; 1997.

10. Kannel WB. Cardiovascular risk factors in the elderly. Coron Artery Dis 1997; 8: 565-75.

11. Rego RA, Berardo FA, Rodrigues SS, et al. Risk factors for chronic non-communicable diseases: a domiciliary survey in the municipality of São Paulo, SP (Brazil). Methodology and preliminary results. Rev Saude Publica 1990; 24: 277-85.

12. Martins IS, Marucci MFN, Cervato AM, Okani ET, Mazzilli RN, Casajus MI. Doenças cardiovasculares ateroscleróticas, dislipidemia, hipertensão, obesidade e diabetes melito em população da área metropolitana da região sudeste do Brasil: II-Dislipidemias. Rev Saúde Pública 1996; 30: 75-84.
13. Fuchs FD, Moreira LB, Moraes RS, Bredemeier M, Cardozo SC. Prevalence of systemic arterial hypertension and associated risk factors in the Porto Alegre metropolitan area. Population-based study. Arq Bras Cardiol 1994, 63: 473-479.

14. Trindade IS, Heineck G, Machado JR, et al. Prevalence of systemic arterial hypertension in the population of Passo Fundo (Brazil) metropolitan area. Arq Bras Cardiol 1998, 71: 127-30.

15. Piccini RX, Victora CG. Systemic arterial hypertension in an urban area of southern Brazil: prevalence and risk factors. Rev Saude Publica 1994, 28 261-7.

16. Vokonas PS, Kannel WB, Cupples LA. Epidemiology and risk of hypertension in the elderly: The Framingham Study. J Hypertens 1988; 6: S3-S9.

17. Burt VL, Whelton P, Roccella EJ, et al. Prevalence of hypertension in the US population. Results from the Third National Health and Nutrition Examination Survey, 1988-91. Hypertens 1995; 25: 305-13.

18. Bulpitt CJ. Blood pressure in the elderly. In: Marmot M and Elliot $\mathrm{P}(\mathrm{ed}) \mathrm{Corona}-$ ry Heart Disease Epidemiology: from aetiology to public health. Oxford University Press: Oxford, 1995.

19. Kannel WB. Cardioprotection and antihypertensive therapy: the key importance of addressing the associated coronary risk factors (The Framingham Experience). Am J Cardiol 1996; 77: 6B-11B.

20. National High Blood Pressure Education Program. National High Blood Pressure Education Program working group report on hypertension in the elderly. Hypertens 1994; 23: 275-85.

21. Duncan BB, Schmidt MI, Achutti AC, Polanczyk CA, Benia LR, Maia AA Socio-economic distribution of non-communicable disease risk factors in urban Brazil: the case of Porto Alegre. Bull Pan Am Health Organ 1992, 27 : 337-49.

22. Wareham NJ, Wong M, Hennings S, et al. Quantifying the association between habitual energy expenditure and blood pressure. Int J Epidemiol 2000; 29: 655-60.

23. Sherman SE, D'Agostino RB, Silbershatz H, Kannel WB. Comparison of past versus recent physical activity in the prevention of premature death and coronary artery disease. Am Heart J 1999; 138: 900-7. 